\title{
Hacia una cultura del agua
}

\author{
Entrevista al Dr. Pedro Arrojo Agudo ${ }^{1}$
}

\section{Cultura de Paz: ¿Cuál es su valoración sobre la situación del recurso agua a nivel mundial?}

Dr. Pedro Arrojo: Se estima que unos 1000 millones de personas no tienen garantizado el acceso a agua potable, lo que motiva, según NNUU unas 10.000 muertes diarias, en su mayoría niños y niñas de menos de 5 años. Tales cifras tan sólo toman en consideración las muertes por diarrea debidas a la ingesta de aguas contaminadas biológicamente; pero no se toman en cuenta los impactos crecientes de la contaminación tóxica por vertidos industriales, de la minería y pesticidas agrarios. La contaminación por metales pesados, que no para de crecer, supone el envenenamiento progresivo de millones de personas, produciendo abortos indeseados, malformaciones congénitas, enfermedades y muertes a medio o largo plazo que no se contabilizan en las estadísticas de NNUU.

\section{Se estima que unos 1000 millones de personas no tienen garantizado el acceso a agua potable, lo que motiva, según NNUU unas 10.000 muertes diarias, en su mayoría niños y niñas de menos de 5 años.}

Por otro lado, los indicadores de biodiversidad sitúan en el medio hídrico continental la mayor proporción de especies extinguidas o en peligro de extinción de la biosfera. En estas condiciones hablar de "Crisis Global

1 Doctor en Ciencias Físicas por la Universidad de Zaragoza, España. Ex Presidente de la Fundación Nueva Cultura del Agua. Profesor en la Facultad de Económicas en Zaragoza. Miembro del Comité MAB (Hombre y Biosfera) de la UNESCO.

\section{RESUMEN}

En esta entrevista realizada al Dr. Arrojo nos habla de la "Crisis Global del Agua". Una crisis que, suele ser más de calidad de las aguas accesibles para los más pobres. Nadie muere propiamente de sed, sino de enfermedades derivadas del agua que se bebe. En este contexto, considerar el agua como una simple mercancía, está transformando a los ciudadanos en simples clientes, con lo que incrementa la vulnerabilidad de los más débiles, dice el autor, quien levanta la necesidad de construir una Nueva Cultura del Agua, basada en el ahorro y la eficiencia, así como en la conservación de los ecosistemas (ríos, lagos, humedales, acuíferos). Una Nueva Cultura del Agua que facilite la ineludible transición del viejo paradigma renacentista de "dominación de la naturaleza" al nuevo paradigma emergente de "sostenibilidad".

Palabras clave: cultura del agua, contaminación, escasez, recurso, mercancía.

\section{ABSTRACT}

In this interview made to Dr. Arrojo, he speaks to us about the "Global Water Crisis". A crisis that, although it is usually presented as a problem of "scarcity", tends to be more a crisis of the quality of water which is accessible to the poorest. Nobody dies of thirst itself, but from diseases caused by the water that people drink. In this context, to consider water as a mere commodity, makes citizens become in simple clients, increasing the vulnerability of the weakest. The Author suggests the need to build a New Water Culture, based on savings and efficiency, as well as the preservation of ecosystems (rivers, lakes, wetlands, aquifers). A New Water Culture that facilitates the inescapable transition from the old Renaissance paradigm of "domination of nature" to the new emerging paradigm of "sustainability".

Key words: Water culture, contamination, scarcity, resource, commodity. 


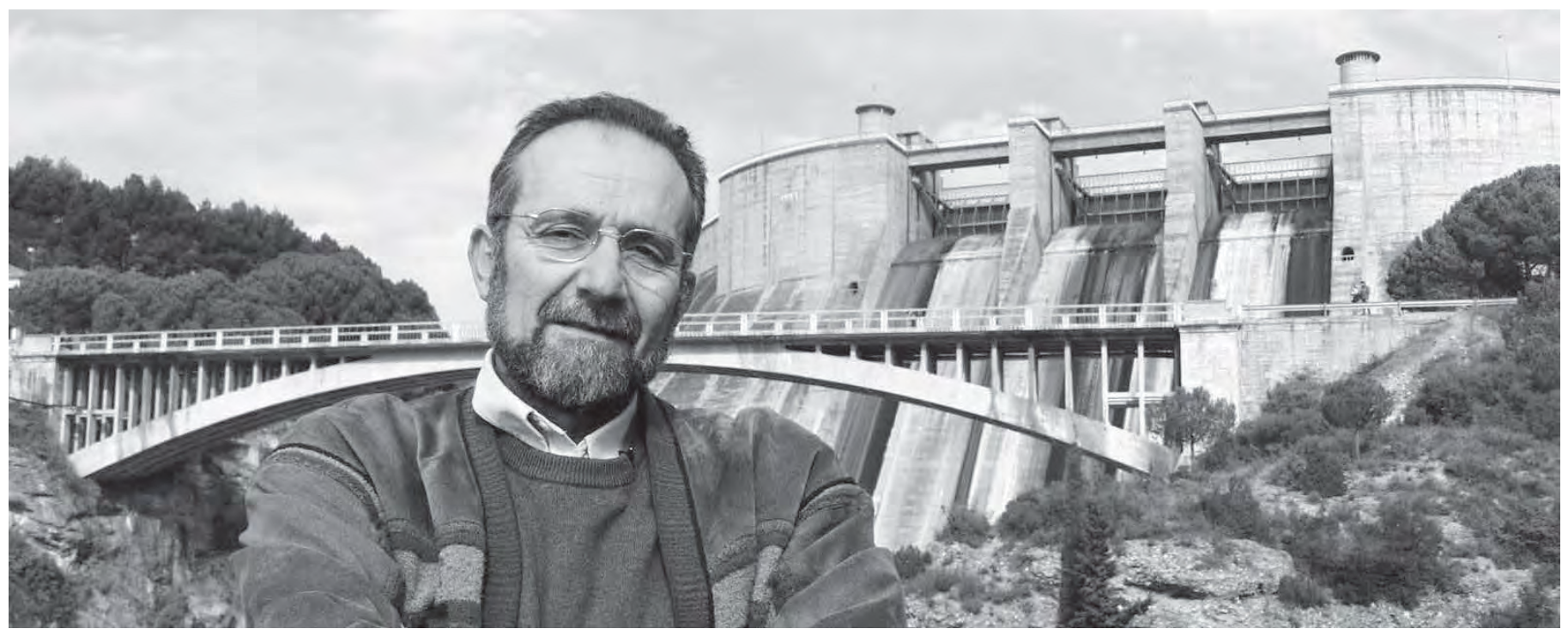

del Agua", paradójicamente en el "Planeta Agua", no es exagerado. Una crisis que, aunque suele presentarse como un problema de "escasez", suele ser más de calidad de las aguas accesibles para los más pobres. Nadie muere propiamente de sed, sino de enfermedades derivadas del agua que se bebe... De hecho, todas las comunidades, desde tiempos ancestrales, se han asentado en las riberas de ríos y lagos, en los entornos de las fuentes o en territorios donde las aguas subterráneas de los acuíferos son accesibles a través de pozos... Desgraciadamente, hemos quebrado la salud de nuestros ecosistemas acuáticos; primero murieron peces y ranas, pero después empezaron a morir personas; eso sí, siempre en las comunidades más pobres y generalmente entre los más vulnerables, los niños ...

En este contexto, la pretendida solución neoliberal de considerar el agua como una simple mercancía, forzando la privatización de los servicios de agua y saneamiento, está transformando a los ciudadanos en simples clientes, con lo que, lejos de resolverse el problema, se incrementa la vulnerabilidad de los más débiles.

Desde mi punto de vista, esta "Crisis Global del Agua" tiene por tanto sus raíces en la convergencia de tres grandes fallas críticas:

La crisis de insostenibilidad provocada sobre nuestros ecosistemas acuáticos
La crisis de inequidad y pobreza derivada de un orden económico inmoral.

La crisis de gobernanza de los servicios de agua y saneamiento, bajo las presiones privatizadoras que impone el neoliberalismo.

\section{C d P: En algunos sectores se plantea que el agua pasa a ser un bien de interés estratégico y que incluso, las futuras guerras en el mundo serán por el control de este recurso.}

Dr. Pedro Arrojo: Cuando se dice eso se suele pensar en el agua como un "recurso escaso"..., como el petróleo. Sin embargo, como ya he explicado, el agua no es propiamente escasa en el "Planeta Agua". El ciclo hídrico regenera diariamente millones y millones de metros cúbicos que se reparten por el mundo. La idea de apropiar agua en la Amazonía para llevarla a EEUU, Europa o China, como si de oro o petróleo se tratara, no tiene sentido. Llevar un metro cúbico de agua desde la Amazonía a Washington costaría del orden de $8 €$, siendo que en Washington las nubes descargan gratuitamente ingentes cantidades de agua dulce de alta calidad cada año. Incluso si se quiere suplantar de forma artificial el proceso de regeneración natural del agua dulce, hoy podemos desalar agua de marporósmosis inversa (usando membranas de baja presión y cámaras isobáricas de recuperación energética) 
a un coste de $0,5 € / \mathrm{m}^{3}$ ( $1 \mathrm{~m}^{3}$ son 1000 litros). Llevar 1 hectómetro cúbico de agua dulce desde el Acuífero Guaraní a Pekín, sería tan absurdo como llevar un millón de toneladas de tierra fértil desde el Congo a Moscú ...

Sin embargo, lo que si tiene sentido para los grandes poderes económicos y políticos del planeta es disponer de esos recursos naturales, generalmente allí donde están, para producir otros bienes que si se pueden transportar y vender donde convenga. Tiene sentido construir una gran represa en Centroamérica para disponer en California de la energía hidroeléctrica que produzca, sin tener que sacrificar e impactar ríos y territorios en EEUU. O tiene sentido producir pasta de papel en el río Paraná, sin gastar dinero en depurar los retornos; o extraer oro devastando, con la minería a cielo abierto, territorios peruanos y dejando relaves tóxicos que envenenarán las aguas y el futuro de generaciones enteras... Dicho en otras palabras, a través del imperio del "libre mercado", se apropian tierras fértiles y aguas de calidad allá donde aún existen para generar negocios en cualquier lugar, aún a costa del bienestar de los pueblos afectados y de la salud del Planeta... Pero el control de esos recursos lo consiguen los poderosos generalmente a través del mercado más que a través de la guerra.

No obstante, es preciso advertir que en la medida que se pueden colapsar y derivar ríos enteros mediante grandes infraestructuras, se generan conflictos internacionales en los que el país más poderoso de la región, como es el caso de Egipto en la cuenca del Nilo, intenta apropiarse, bajo amenaza militar, de las utilidades que pueden extraerse de todo un río ... En otros casos, como en Oriente Medio, el agua llega a usarse como un arma de chantaje y dominación sobre todo un pueblo, en este caso el palestino por parte de Israel, ante el silencio vergonzoso y cómplice de la llamada comunidad internacional...

A pesar de todo, en la mayoría de los casos, los ríos han unido, comunicado y hermanado a los pueblos ribereños. Hay muchos más tratados de colaboración internacional entre pueblos que comparten cuencas fluviales que confrontaciones bélicas por apropiar sus aguas...

\section{$C d P:$ ¿A qué se le llama cultura del agua?}

Dr. Pedro Arrojo: Desde mediados de los 90, en España promovimos un movimiento social que llegó a movilizar, a principios de la siguiente década, a más de 1 millón de personas contra el llamado Plan Hidrológico Nacional, que proyectaba una nueva oleada de grandes presas que inundaban pueblos, así como de grandes trasvases que amenazaban la sostenibilidad de muchos ríos, como el Ebro. Un gran movimiento ciudadano que viene exigiendo superar la tradicional mitificación productivista del hormigón (concreto) para promover una Nueva Cultura del Agua, basada en el ahorro y la eficiencia, así como en la conservación de los ecosistemas (ríos, lagos, humedales,

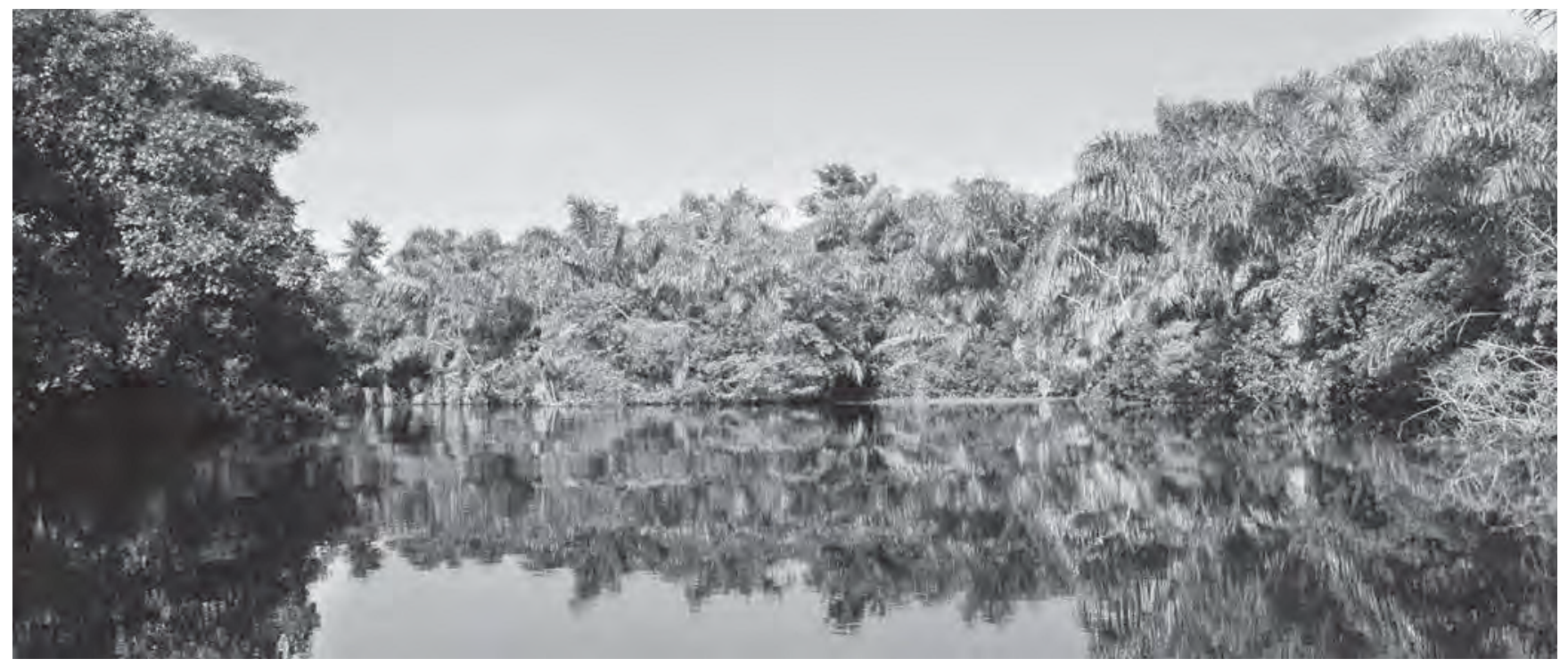

Foto: Manuel Esquivel 


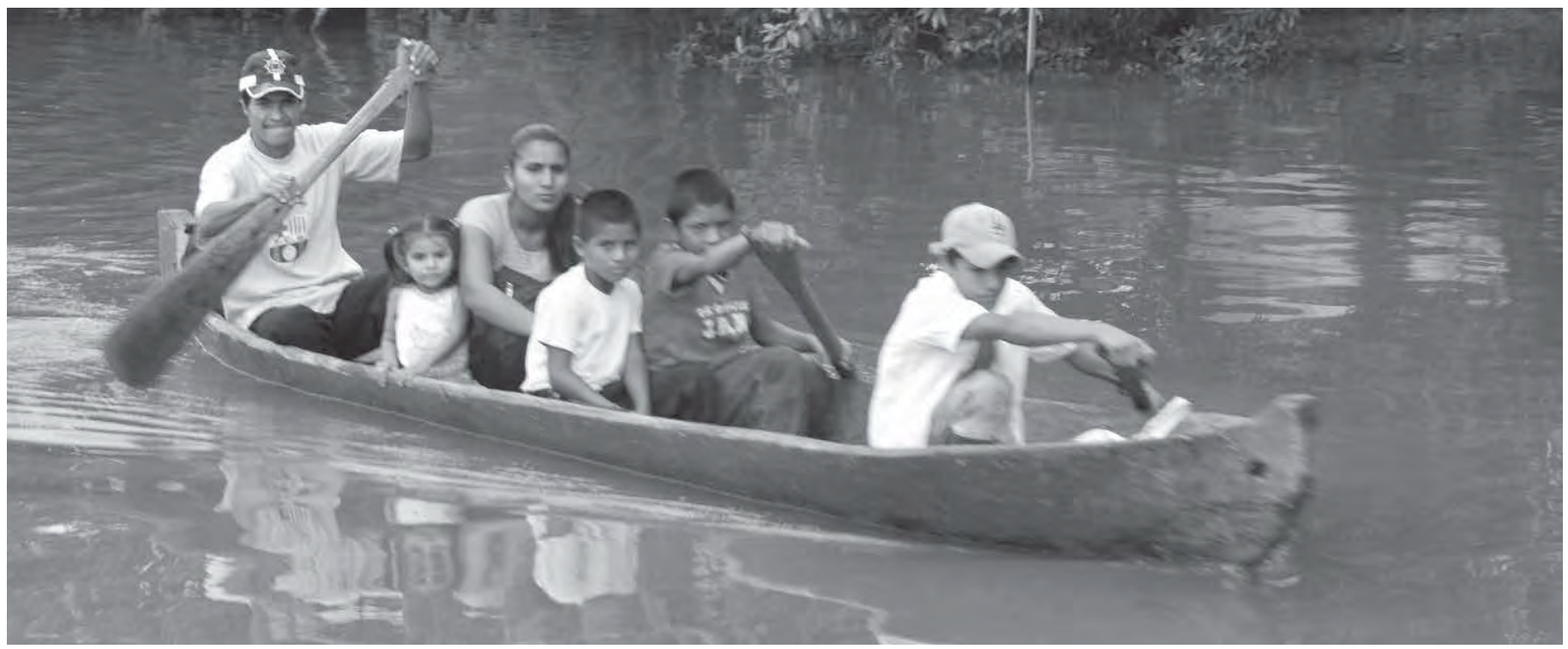

Foto: Manuel Esquivel

acuíferos). Una Nueva Cultura del Agua que facilite la ineludible transición del viejo paradigma renacentista de "dominación de la naturaleza" al nuevo paradigma emergente de "sostenibilidad". Al igual que empezamos a entender que un bosque es mucho más que un almacén de madera, se trata de asumir que los ríos no pueden seguir siendo considerados simples "canales de $\mathrm{H}_{2} \mathrm{O}$ ", sino que debemos empezar a gestionarlos como ecosistemas vivos.

La Nueva Cultura del Agua viene promoviendo transitar de la tradicional visión de recurso a nuevos enfoques de gestión ecosistémica; pasar de la gestión del agua como simple "recurso", a la gestión de cuencas fluviales; de la misma forma que transitamos de la gestión maderera a la gestión forestal, asumiendo nuevas perspectivas de sostenibilidad, sustentadas en el principio ético de la equidad intergeneracional. Desde esta visión, emerge un nuevo enfoque de racionalidad económica que integra valores ambientales y sociales, que no por intangibles, desde la lógica del mercado, son menos valiosos para la sociedad actual y para la vida.
Hoy, de hecho, la vieja Europa, al igual que otros países, como EEUU, Sudáfrica o Australia, vienen aprobando nuevas leyes basadas en esa visión ecosistémica. La UE en el 2000, al calor de ese movimiento por la Nueva Cultura del Agua, aprobó la llamada Directiva Marco de Aguas, un nuevo marco legal que asume como objetivo central la recuperación del Buen Estado Ecológico de los ríos, lagos, humedales y acuíferos europeos. Más allá de la exigencia de calidad físico-química de las aguas, la ley exige recuperar la biodiversidad del medio hídrico y de sus entornos, como garantía de que los ecosistemas acuáticos recuperan su funcionalidad. Desgraciadamente, todo ello no es expresión tanto de una reconversión ética como de un ejercicio de pragmatismo economicista. El mundo anglosajón ha entendido más rápidamente que el mundo latino la fábula de la gallina de los huevos de oro... No es que le tengan propiamente amor a la gallina, sino a los huevos de oro que pone cada mañana. Y han llegado a la conclusión de que es "inteligente" cuidar al animal... Han entendido que cortar un bosque a mata-rasa es un buen negocio para la empresa que se lleva la madera, pero un verdadero desastre económico para el país que lo permite. De igual forma que, contaminar o sobreexplotar un río o un acuífero, enriquece a corto plazo a algunos pero acaba arruinando al conjunto de la sociedad ... Hoy empezamos a entender que no tiene sentido económico, por un lado, degradar las complejas infraestructuras naturales del ciclo hídrico (ríos, lagos, humedales y acuíferos), que usando sofisticadas tecnologías naturales 
de energía solar gratuita regeneran ingentes cantidades de aguas de alta calidad, para acabar pagando, por otro lado, 1000 euros por un metro cúbico de las aguas que embotellamos...

\section{$C d P$ : También se empieza a hablar del agua como un nuevo derecho humano ¿en qué consiste esta nueva normatividad y qué valor y alcance tiene?}

Dr. Pedro Arrojo: Con esta pregunta, más allá de la vertiente ambiental, se introduce la vertiente social de esa Nueva Cultura del Agua de la que estamos hablando; aunque debo advertir que, desde Europa, lejos de aportar nada en este campo, estamos aprendiendo de otros continentes y muy especialmente de América Latina. La Guerra del Agua de Cochabamba, contra la privatización del agua abrió la reivindicación del acceso al agua potable y al saneamiento como un derecho humano, que finalmente, en 2010, la Asamblea General de NNUU reconoció, a propuesta de Bolivia. En definitiva, lo que está sobre la mesa, más allá del reto de la sostenibilidad de los ecosistemas acuáticos, es si el agua que derivamos de ellos debe ser gestionada como un simple bien económico a través de la lógica de mercado, tal y como exige la visión neoliberal, o si debe ser considerada como un bien común a administrar desde nuevas formas de gestión pública participativa. Se abre así un debate que, más allá de la política, implica un debate ético.

Estoy seguro que la humanidad, y no sólo Europa o EEUU, acabará haciendo las paces con ríos, lagos y humedales, aunque sólo sea por la cuenta que nos trae... Supongamos en todo caso que llegará ese día en el que supiéramos obtener la madera y el agua que necesitamos, pero respetando la sostenibilidad de nuestros bosques y de nuestros ríos... Pues bien, ese día, superado el reto de la sostenibilidad ambiental, tendríamos aún que abordar el reto ético del buen uso del agua que usamos... En el caso de la madera, una vez garantizada la sostenibilidad del bosque, entenderemos natural que el leñador venda los troncos cortados al industrial maderero, que venderá las tablas al carpintero, que a su vez fabricará muebles que nos venderá a unos u otros... Es decir, asegurando las medidas de regulación pertinentes, parece razonable que el mercado articule la gestión del recurso maderero ...

Sin embargo, si hacemos algo parecido con el agua que detraemos de ríos y acuíferos, cometeremos un grave

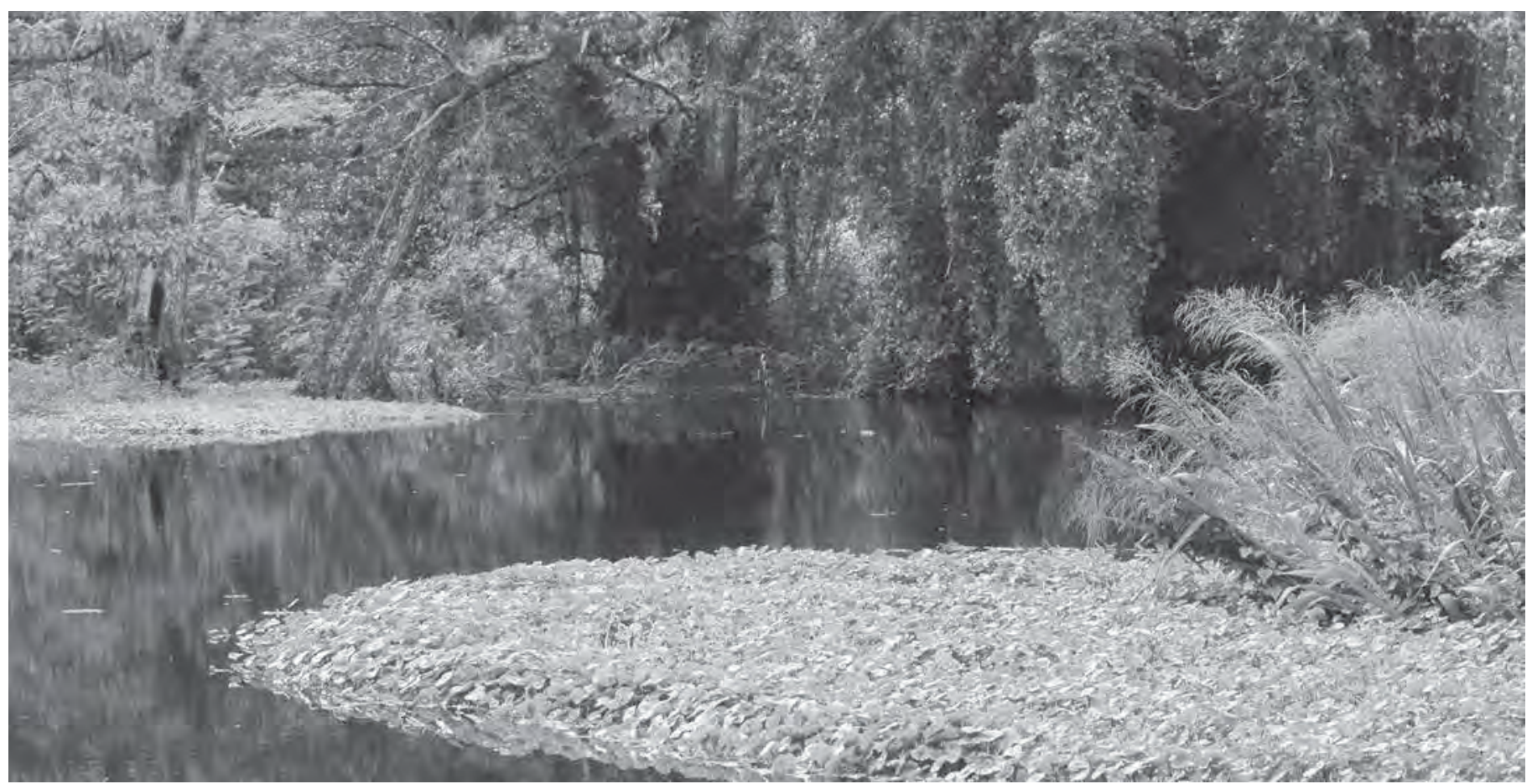

Foto: Manuel Esquivel 
error; porque, a diferencia de otros recursos naturales renovables, como la madera, cuyas utilidades son consistentemente sustituibles por bienes de capital (dinero), las principales funciones y valores derivados del uso del agua no lo son. Lo importante del agua no es su materialidad, $\mathrm{H}_{2} \mathrm{O}$, sino la diversidad de esas funciones y valores en juego y que desbordan la lógica del mercado. Por ello desde la Nueva Cultura del Agua se propone una reflexión que permita categorizar éticamente esa diversidad de usos, valores y funciones del agua, distinguiendo:

- El agua-vida, en funciones básicas de supervivencia, tanto de los humanos, como de los demás seres vivos, debe ser priorizada, de forma que se garantice la sostenibilidad de los ecosistemas y el acceso de todos a cuotas básicas de aguas de calidad, como un derecho humano (40 litros/persona/día es apenas el 1,2\% del agua que usamos). En este ámbito debe incluirse el agua necesaria para producir los alimentos de los que depende la suficiencia y la soberanía alimentaria de comunidades vulnerables.

- El agua-ciudadanía, en funciones de salud y cohesión social (como los servicios domiciliarios de agua y saneamiento), debe situarse en un segundo nivel de prioridad, en conexión con el interés general de la sociedad y en el ámbito de los derechos de ciudadanía, vinculados a los correspondientes deberes ciudadanos. En este sentido, deben promoverse modelos de gestión pública participativa bajo control social y sistemas tarifarios bajo criterios sociales de redistribución de costes que permitan financiar servicios eficientes de acceso universal.

- El agua-economía, en funciones productivas, más allá del nivel de suficiencia, genera beneficios en el ejercicio del legítimo derecho de unos y otros a mejorar nuestro nivel de vida; derecho que debe gestionarse desde un tercer nivel de prioridad, implantando criterios de racionalidad y responsabilidad económica. Representa la mayor parte del agua usada y genera los principales problemas de contaminación. En este ámbito, más allá de madurar socialmente lo que debe considerarse por nivel de suficiencia, es preciso priorizar el derecho al desarrollo de los más pobres, aplicando criterios de equidad social e interterritorial.

\section{En suma, no se trata de considerar como un derecho humano el uso del agua en cualquier actividad, como puede ser fabricar pasta de papel, regar algodón para la exportación o llenar una piscina ... Se trata de ubicar los diversos usos y valores en juego en las categorías éticas reseñadas a fin de ordenar prioridades, articular objetivos y fijar criterios de gestión consistentes en cada caso, garantizando la máxima prioridad al acceso al agua potable y al saneamiento básico como un derecho humano. \\ $C d P$ : Algunos países tienen mantos acuíferos privilegiados, sin embargo, en algunos casos prima el interés de proyectos considerados también estratégicos, como la construcción de un canal interoceánico, en la balanza ¿qué es más importante en términos
del desarrollo futuro de un país?}

Dr. Pedro Arrojo: He oído hablar del proyecto de canal interoceánico en Nicaragua y de la controversia que genera, pero la verdad es que no lo he estudiado y por tanto no tengo argumentos sólidos y específicos al respecto. No obstante, sí he estudiado otros grandes proyectos hidráulicos - como represas y trasvases intercuencas - justificados de forma similar a como se está argumentando la necesidad y la bondad de este proyecto y, desde esa experiencia, recomiendo que este tipo de obras se analicen y debatan con tiempo y con suma prudencia, considerando pros y contras en el corto, medio y largo plazo. Lógicamente, la envergadura de estas infraestructuras supone inexorablemente grandes impactos sobre el orden natural y los ecosistemas que vertebran los territorios, así como sobre las poblaciones afectadas, que en general tienden a subestimarse desde la tradicional arrogancia tecnocrática que impera en los medios científico-técnicos. 
El hecho, por otro lado, de que tras estos proyectos se escondan enormes intereses financieros y empresariales transnacionales suele mover capacidades de cooptación de voluntades y de propaganda mediática que dificultan enormemente un debate técnico y social limpio y democrático. Por último, me preocupa la manipulación política que puede y suele hacerse con este tipo de grandes proyectos, en la medida que es fácil mitificarlos ante la opinión pública como fuentes de riqueza y de progreso para todos ... Insisto en todo caso que no pretendo decir que en Nicaragua se esté manipulando el debate sobre el canal interoceánico desde estos posibles sesgos e intereses creados, pues, como he dicho no conozco a fondo el proyecto y menos la forma como se está debatiendo...

Aportaré simplemente algunos datos sobre megaproyectos hidráulicos que sí he estudiado y sobre las tendencias que en este tipo de grandes obras se perciben. en forma de préstamos que gravitan sobre la deuda pública, costes de seguridad (vigilancia o acciones policiales o del ejército ...), procesos de expropiación o asunción de riesgos (¿quién asume hoy en Japón, por ejemplo, los costes económicos del desastre de Fukushima? ... por no hablar de otros costes impagables...).

- Los impactos socio-ambientales, en gran medida intangibles, suelen ignorarse o minimizarse, especialmente en lo que se refiere a impactos de largo plazo sobre generaciones futuras...

- Igualmente tienden a infravalorarse los impactos en el medio rural sobre comunidades y poblaciones pobres, especialmente cuando se trata de comunidades indígenas. Basta recordar a cuanto se indemnizaron las vidas humanas y las graves afecciones a la salud en Bohpal (India), más allá de daños materiales, y comparar con lo que se habría tenido que pagar en Manhattan.

- Según crece la envergadura de las infraestructuras se suele transitar de las "economías de escala", que tienden a incrementar la rentabilidad, a lo que se denominan "deseconomías de escala" que deshacen dicha rentabilidad.

- Según se avanza en el desarrollo de nuevas infraestructuras, emerge la acción inexorable de la ley de los "costes marginales crecientes y beneficios tiempo que, a la postre, suelen emerge
cruzados y sinergias inesperadas que multiplican su gravedad. Por ello, en las legislaciones más avanzadas se suele exigir, más allá de la evaluación ambiental puntual decadaintervención (en el conjunto del proyecto), una evaluación estratégica que identifique esas sinergias complejas (que llevan a que los impactos dejen de ser aditivos y se produzcan efectos multiplicativos o exponenciales...).

- En la medida que se presentan en el ámbito del "interés general", los estados suelen asumir costes económicos y riesgos que no se contabilizan de forma rigurosa en el balance coste-beneficio del proyecto:

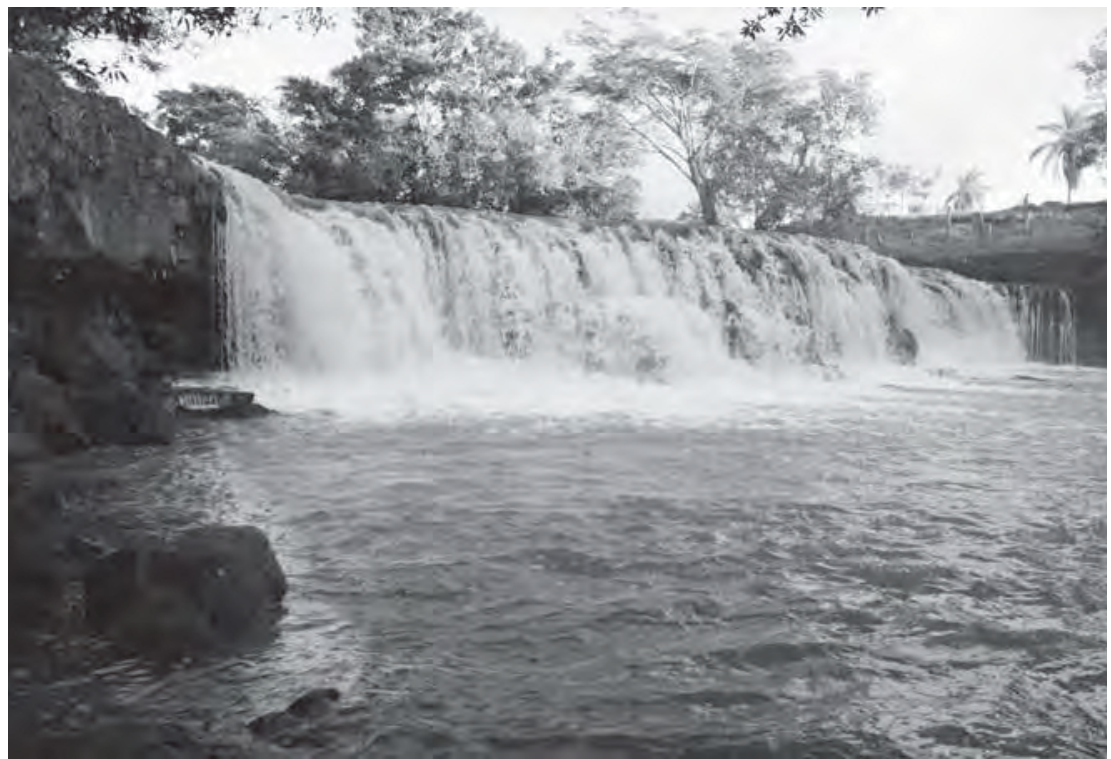

Foto: Manuel Esquivel 
marginales decrecientes" que erosiona la rentabilidad de los sucesivos y cada vez mayores proyectos. Sirva de ejemplo al respecto la valoración oficial del Geological Survey de EEUU según la cual, la eficiencia de regulación (volumen regulado/capacidad) de las 100 mayores represas construidas en EEUU ha ido decayendo hasta dividirse por 35 .

- Con frecuencia estas grandes infraestructuras acaban afectando derechos humanos de comunidades vulnerables, lo que lleva a cuestionar su legitimidad.

Todo ello está llevando a discutir críticamente la rentabilidad real de determinadas mega-infraestructuras que, no obstante, siguen promoviéndose, especialmente en países como China en los que el nivel democrático deja cuando menos mucho que desear. Igualmente suelen llevarse adelante, a veces, en países empobrecidos bajo argumentos engañosos de corte desarrollista, "cuesten lo que cuesten", con el Estado en última instancia como garante de negocios privados sometidos a fuertes incertidumbres ...

\section{$C \boldsymbol{d} P$ : ¿Cómo afecta el cambio climático a la existencia y disponibilidad de aguas dulces?}

Dr. Pedro Arrojo: El cambio climático en curso no va a alterar la cantidad de agua de la biosfera sino el

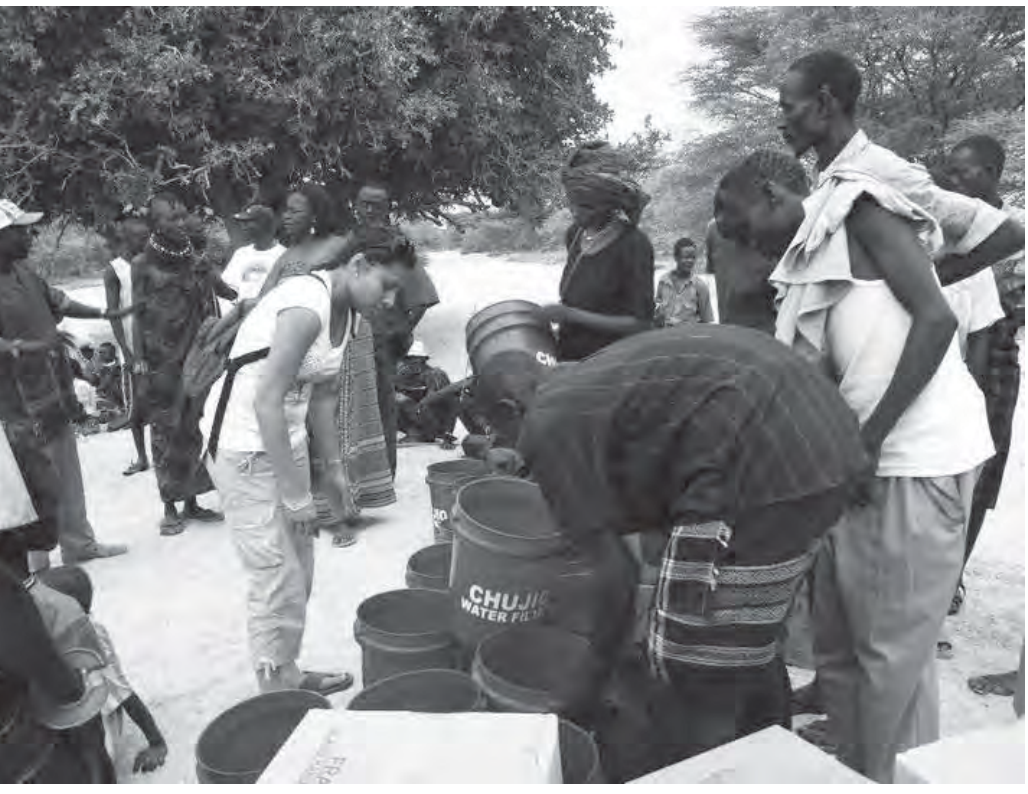

Foto: Laura Padovani ritmo y distribución de la pluviometría. Puede incluso esperarse que el aumento de las temperaturas lleve, entre otros efectos, a aumentar la evaporación de masas de aguas, con lo que puede intensificarse el ciclo y las precipitaciones globales... En suma, el cambio climático en curso no apunta a un planeta marrón y seco; el planeta seguirá siendo azul. Los impactos sobre el ciclo hídrico en continentes e islas se centran fundamentalmente en dos ejes:

1. Cambio acelerado de patrones climáticos e incremento de la variabilidad climática y pluviométrica, aumentando los eventos extremos de sequía y tormentas, huracanes etc..., tanto en intensidad como en frecuencia.

2. Incremento de la temperatura media con el correspondiente aumento en la evapotranspiración de las masas vegetales (cultivadas o silvestres) y la desaparición de paquetes glaciares y nivales en cabeceras de cuenca.

El incremento en frecuencia e intensidad de ciclos de sequía y precipitaciones bruscas y masivas, en un marco general de cambio de patrones climáticos, disparan la vulnerabilidad de las comunidades y pueblos con menos medios, no sólo frente a fenómenos catastróficos sino ante el cambio de condiciones que repercuten en la producción de alimentos.

Por otro lado, se agravarán y acelerarán los fenómenos en curso de erosión de suelos y desertización, reduciéndose la tasa de infiltración a los acuíferos y aumentando la escorrentía superficial. Este debilitamiento de la acción reguladora de los acuíferos junto con la desaparición de masas nivales y glaciares en cabeceras de cuenca incrementará la irregularidad de los caudales fluviales, aumentando los riesgos derivados de las crecidas y sequías, y reduciéndose la disponibilidad efectiva de agua aún en escenarios en que la pluviometría media se mantenga más o menos constante.

El crecimiento de las temperaturas medias comportará aumentos severos de la evapotranspiración de las masas vegetales, lo que supondrá, por ejemplo en España, reducciones en los caudales fluviales que se estima oscilarán entre el $25 \%$ y el $50 \%$. 


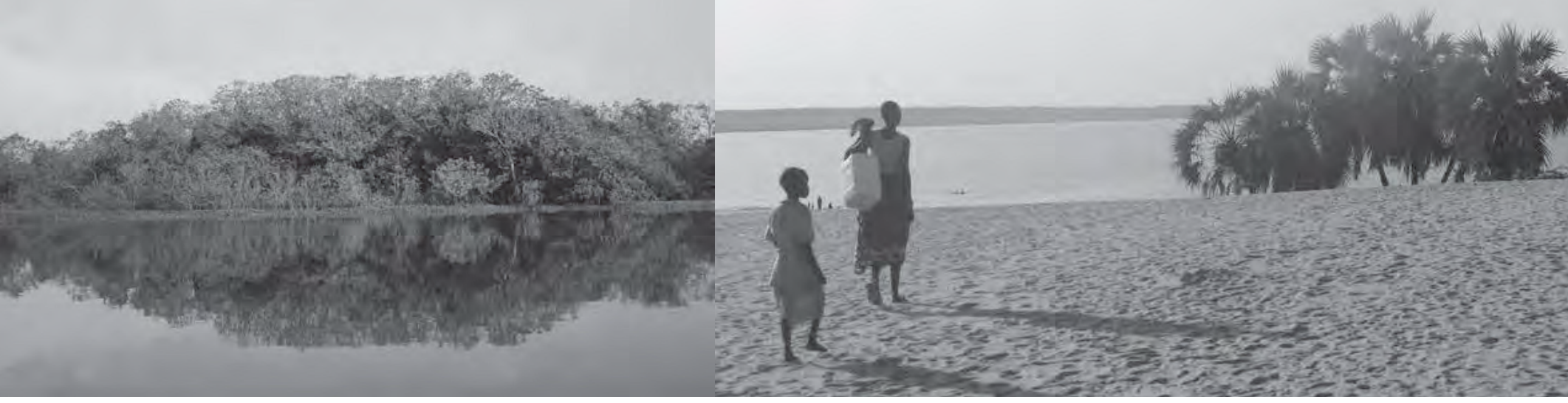

\section{$C \boldsymbol{d} \boldsymbol{P}$ : ¿Podríamos prescindir del agua dulce natural y reemplazarla por la transformación de agua salada en dulce, considerando que los océanos son las más grandes reservas de éste líquido?}

Dr. Pedro Arrojo: Las tecnologías de desalación han avanzado aceleradamente a lo largo de la última década en el campo de la ósmosis inversa, consiguiéndose reducir los costes energéticos al entorno de $3 \mathrm{kwh} / \mathrm{m}^{3}$, cerca ya del mínimo termodinámico; al tiempo que los costes monetarios se han reducido igualmente situándose en el entorno de $0,5 € / \mathrm{m}^{3}$. Ello hace viable aplicar masivamente estas tecnologías para determinados usos que exigen alta calidad en las aguas, como es la obtención de aguas potables.

Sin embargo, si los caudales desalados en línea de costa tienen que bombearse a zonas de interior, los costes tenderán a ser inviables. Por otro lado, aún en zonas cercanas a la costa, la desalación es impagable para buena parte de los cultivos de regadío, especialmente los de carácter extensivo; de igual forma que será impagable para comunidades y sectores sociales empobrecidos. Por último debemos ser conscientes de que, aún en los casos en que resulte viable económicamente, estamos trasladando problemas de insostenibilidad hídrica al campo de la insostenibilidad energética...
En resumen, cuando las demandas se producen en línea de costa, sin duda las modernas tecnologías de desalación son hoy una alternativa más económica y razonable que las estrategias tradicionales de grandes represas y trasvases a larga distancia. Sin embargo no podemos mitificar estas nuevas tecnologías y tendremos que aplicarlas con prudencia y sin olvidar que con ellas acabamos haciendo, en el mejor de los casos, lo que la naturaleza hace gratis a través del ciclo hídrico, pero con balance gravoso, tanto en términos financieros como energéticos...

\section{$C d P: ¿$ Existen experimentos de hidratación humana que utilicen otros elementos y que prescindan del agua?}

Dr. Pedro Arrojo: No. El agua es en este sentido un bien insustituible en lo que se refiere a las funciones básicas que cumple en las formas de vida conocidas, siendo imprescindible e insustituible tanto para la ingesta humana como para la producción de alimentos. Obviamente hay otros usos de refrigeración, dilución, evacuación de residuos, producción energética y determinadas utilidades productivas en las que el agua puede ser sustituida por otros elementos y tecnologías alternativas, aunque en muchos casos tales alternativas imponen costes superiores que pueden resultar inviables. 


\section{$C \boldsymbol{d} \boldsymbol{P}$ : ¿Dónde se concentran las mayores reservas de agua dulce en el mundo?}

Dr. Pedro Arrojo: Cuando se habla en términos cuantitativos de "reservas de agua dulce", desde una visión de recurso para generar riqueza económica, se suele desenfocar la valoración. Considerar por ejemplo que la Amazonía representa una de las mayores reservas de agua dulce, suele llevar a pensar que podríamos extraer y usar toda esa agua en actividades productivas, sin entender que los propios ecosistemas amazónicos requieren la mayor parte de esos caudales para sostener la vida que sustentan. Comparar el caudal de un río en cabecera con el que lleva en el delta de su desembocadura puede llevar a

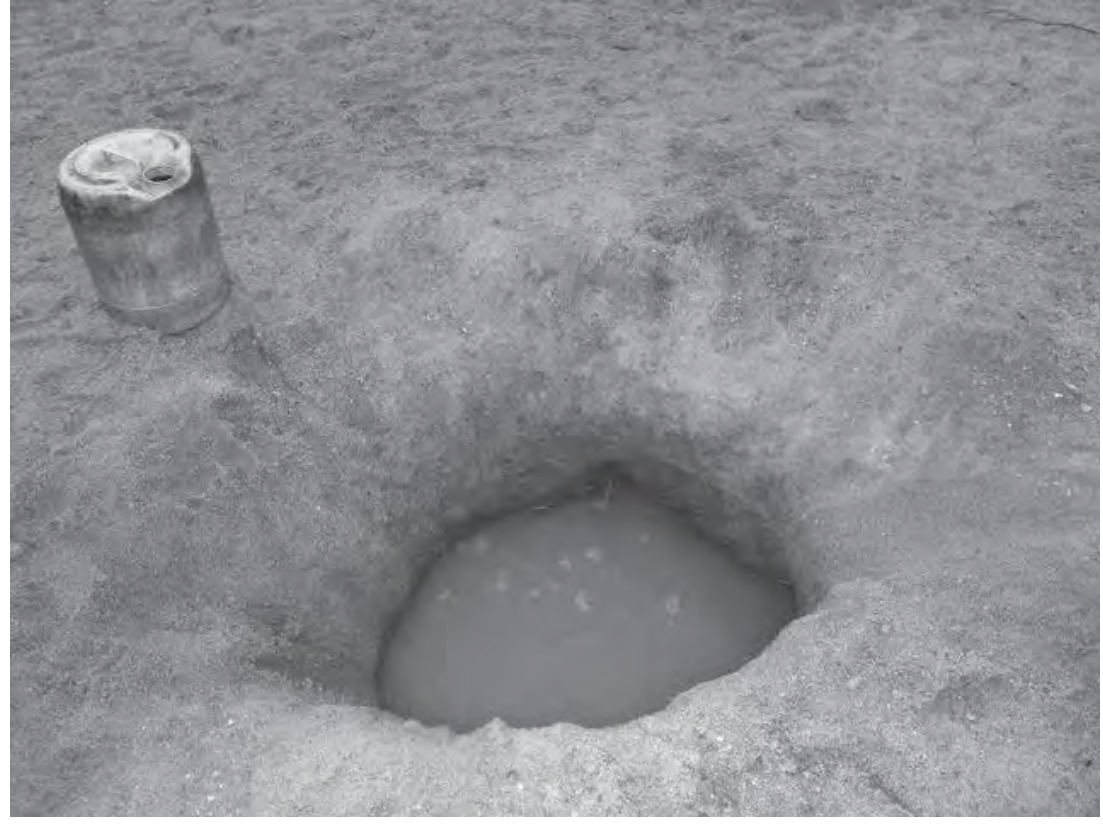

Foto: Laura Padovani pensar que en dicho delta hay una enorme riqueza de agua disponible, frente a la "escasa" que circula en su nacimiento... Sin embargo, desde una visión ecosistémica ese delta puede sufrir una grave crisis de subsidencia, salinización y crisis biológica al no recibir los caudales líquidos, sólidos y de nutrientes suficientes que el río necesita para sustentar los ecosistemas deltaicos y costeros en ese tramo final... Desde esa visión ecosistémica la disponibilidad de agua dulce la genera el ciclo hídrico en volúmenes que dependen de las necesidades ambientales a preservar. En cada tramo fluvial, lago y acuífero se debe por tanto determinar qué volúmenes pueden realmente considerarse como disponibles, pero descontando los requerimientos ambientales mínimos a respetar.

\section{C d P : ¿Se debe formular una estrategia mundial de preservación y distribución del recurso agua que contribuya a preservar el bienestar de los seres humanos y la paz mundial?}

Dr. Pedro Arrojo: La gestión de aguas ha sido tradicionalmente un reto de carácter local o regional. Cada comunidad, asentada en el entorno de un río, lago, fuente o en una zona donde las aguas subterráneas son accesibles, ha administrado la captación de recursos y el

uso de esos ecosistemas. La posibilidad técnica de regular grandes caudales, mediante represas, y transportarlos a grandes distancias, mediante canales y bombeos, ha ampliado no obstante el ámbito geográfico de la moderna gestión de aguas. Sin embargo, la envergadura de los impactos que vamos generando sobre esos ecosistemas, por detracciones masivas o por vertidos sistemáticos, y los desmedidos costes económicos que suponen, llevan a promover estrategias e instituciones de gestión que se recomienda articular a nivel de cuenca.

Obviamente, en cada región y dependiendo de las posibilidades y oportunidades viables de desarrollar actividades de riego, industriales o de servicios, se requieren más o menos caudales de agua. La disponibilidad propiamente de agua no implica en absoluto que la región sea rica o no. En España, por ejemplo, Galicia es la región más húmeda y sin embargo es también la más pobre, mientras que la Costa Mediterránea, semiárida y con baja pluviometría, es la más rica ... De hecho, es en los territorios semiáridos y soleados donde el agua genera mayores oportunidades productivas en la agricultura, a través del regadío, en la medida que se pueden combinar sol y agua ... Si al agua y sol se añade la playa, las demandas se refuerzan por los requerimientos del negocio urbano-turístico, intensificando la sobreexplotación de los ecosistemas acuáticos. En este contexto, se suele hablar de "déficit de 
agua"y se exigen más y más infraestructuras hidráulicas, represas y trasvases... Paradójicamente, en este tipo de territorios semiáridos, donde el agua genera buenos negocios, es donde se acaban produciendo los mayores consumos de agua.En Almería, por ejemplo, sobre la costa mediterránea del sudeste español, un territorio donde apenas llueve, los seres humanos venimos consumiendo del orden de 3 toneladas de agua por habitante y día, en media, es decir 3000 litros/hab/día. Cuando en Almería se descubrió el acuífero de Dalías, alimentado por las aguas del deshielo de Sierra Nevada, se empezaron a hacer cultivos intensivos en invernaderos. El negocio de exportar hortalizas en invierno al resto de Europa hizo crecer la superficie regada, hasta que, cuando la superficie bajo plástico superaba las 9000 hectáreas, se tuvo que declarar "sobreexplotado" el acuífero y prohibir legalmente hacer nuevos pozos y extender más invernaderos.A pesar de ello, dos décadas después se cultivaban 27.000 hectáreas... Por otra parte, al estar en línea de costa, creció el negocio urbano-turístico, con piscinas y campos de golf... El resultado final es un consumo medio de 3000 litros/persona/día que tiende a crecer, lo que lleva a demandar un gran trasvase desde el Ebro (a $800 \mathrm{~km}$ ) pagado por el Estado... En casos así, la pregunta que cabe hacerse es si confrontamos propiamente problemas de "déficit de agua" o de "exceso de ambición"...

Desde mi punto de vista, los problemas de gestión de aguas deben abordarse y resolverse fundamentalmente a nivel local o en el ámbito de la cuenca. Obviamente, las tecnologías hidráulicas disponibles nos permiten gestionar caudales en ámbitos territoriales más amplios; y a menudo, las grandes urbes y ciertos desarrollos

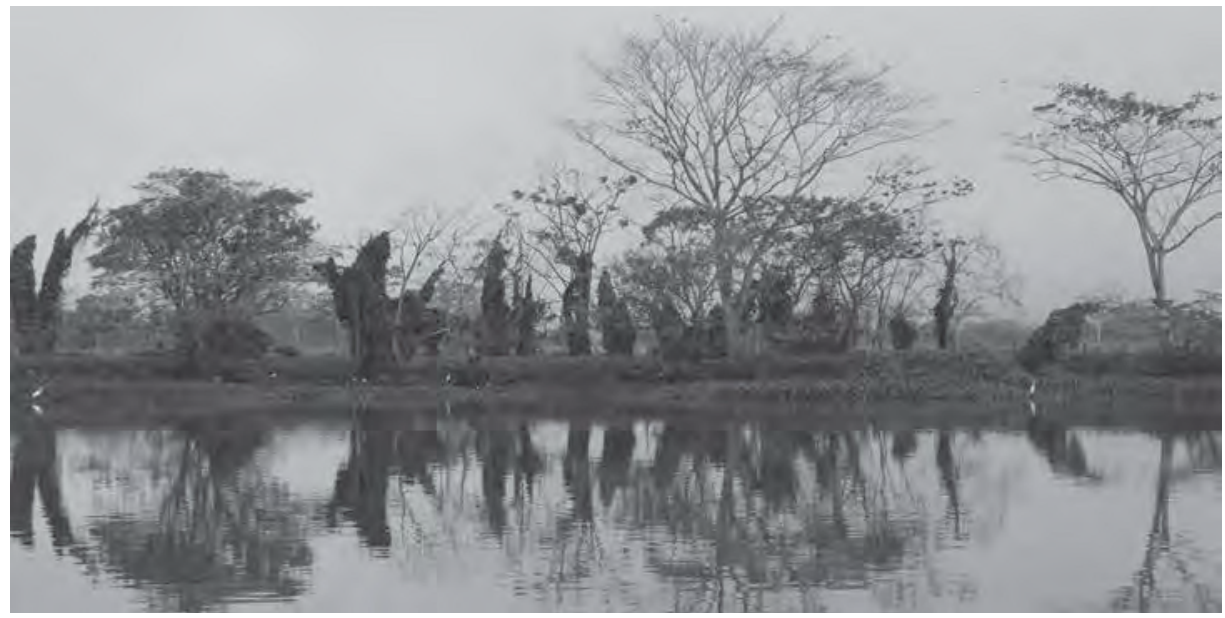

Foto: Manuel Esquivel económicos sólo son posibles construyendo grandes infraestructuras que muevan caudales de unas regiones a otras, a grandes distancias... Sin embargo, desde la experiencia de construcción de grandes represas y trasvases, acabamos llegando a la conclusión de que los costes económicos y los impactos ambientales y sociales, suelen ser demasiado altos. Por ello, en los países donde se han desarrollado legislaciones más avanzadas en la materia, se tiende a abandonar esas estrategias de grandes infraestructuras para promover nuevos enfoques de gestión que priorizan la eficiencia en el uso y la recuperación y conservación de los ecosistemas acuáticos que nos abastecen en el propio territorio, asumiendo criterios de sostenibilidad, frente al mito del crecimiento ilimitado en las demandas de aguas.

En todo caso, cada vez se hace más necesario promover una legislación internacional que permita gestionar las cuencas y acuíferos transfronterizos, asumiendo una visión ecosistémica y solidaria por encima de pretendidas soberanías nacionales que los ríos, los mares y la atmósfera no entienden ... En el marco de la UE, de hecho, estamos ya obligados a diseñar y gestionar planes de cuenca entre los países y poblaciones que compartimos cuencas transfronterizas... La contaminación y detracción abusiva de caudales en el río Tajo, por ejemplo, ha dejado de ser un problema sólo de los portugueses, aguas abajo, para ser una responsabilidad de todos los que viven en la cuenca, españoles y portugueses ... Los problemas de Lisboa pasan así a ser, en buena medida, responsabilidad de los madrileños que afectan al río en su cabecera...

Al igual que los intereses compartidos en materia de navegación fluvial han inspirado multituddetratadosinternacionales en ríos transfronterizos, la gestión integrada y sostenible de estos ecosistemas requiere cada vez de forma más clamorosa leyes e instituciones internacionales que permitan promover la paz, la colaboración y el hermanamiento de los pueblos ribereños, como tradicionalmente ha ocurrido. 